and call them "fracture like appearances." Rib fractures are difficult to recognise early, especially if oblique views are not obtained, and may become visible radiologically only when callus begins to form. Thus rib fractures that become evident only in hospital may not necessarily have occurred in hospital.

Vomiting and diarrhoea are so frequent in infancy that their presence can hardly be used to confirm a diagnosis of copper deficiency. The physiological anaemia at a few months of age or the anaemia that occurs as a result of acute blood loss with fractures and subdural haematomas must be differentiated from the anaemia of copper deficiency.

Twin pregnancies are not an established risk factor for copper deficiency. Similarly, other statements made by Dr Paterson that bleeding from the mouth and blue sclerae are recognised features are totally without foundation. ${ }^{12}$ There is no evidence that a ragged frenulum is a manifestation of a collagen defect.

Dr Paterson's involvement in the cases he describes is usually at a later stage, when parents have been charged and may already be committed to the Crown Court. The absence of social risk factors does not exclude a diagnosis of nonaccidental injury. Further investigation will indeed be necessary before we can diagnose temporary brittle bones with spontaneous cure in the absence of a change of diet.

Children's Hospital,

STEPHEN CHAPMAN

Birmingham B16 8ET

1 Sharron H. The influence of the Paterson factor. Social Work Today 1987;18:8-9.

2 Sharron H. When child abuse is copper deficiency. General Practitioner 1987; Mar 27:45.

\section{Bone mineral density in Addison's disease}

SIR,--Ever since Urist and Vincent in Los Angeles and Hollo and Feher in Budapest showed that the urinary excretion of androgen metabolites was lower in patients with postmenopausal osteoporosis than in age matched controls the interest in this subject has never faded, ${ }^{12}$ particularly as Hollo et al later showed low concentrations of dehydroepiandrosterone in the plasma of patients with osteoporosis. ${ }^{3}$

Though Dr R G Crilly (6 June, p 1486) has been associated with the most convincing data pinpointing lowered adrenal sex hormone concentrations in patients with osteoporosis, ${ }^{45}$ and although these data have been confirmed by the relation between adrenal steroids and some densitometric measurements, there is still considerable disagreement about the adrenopause. Several groups have detected no decrease in adrenal sex steroid concentrations in patients with accelerated osteoporosis. ${ }^{6-10}$ This may be because the actual difference may be rather slim. For example, in the paper by $\mathrm{Dr}$ Crilly and colleagues, in a figure comparing 45 patients with osteoporosis and 45 controls, "a just significant difference in androstenedione levels" was observed, whereas in the next figure, comparing 25 pairs of controls and age matched patients with osteoporosis, significance was not achieved for androstenedione concentration but for plasma cortisol concentrations, which were increased in patients with the crushed vertebrae syndrome. ${ }^{5}$ Perhaps a more sophisticated approach is needed, such as measurement of rates of production of androstenedione or, even better, peripheral conversion rates, as performed by Longcope $e t a l$, who concluded that the amount of biologically available androgen was decreased in patients with osteoporosis."

These are the reasons why we did not discuss in detail in our paper (28 March, p: 798) the pathogenetic role of the adrenopause in postmenopausal osteoporosis. In fact, we agree with most of Dr Crilly's points and believe that our data added much weight to his arguments. Our purpose was to clarify an important pathophysiological pointnamely, that whereas the best way to pinpoint the role of gonadal steroids is to study the consequences of ovarian failure or oophorectomy, so the role of adrenal steroids may be studied best in patients with Addison's disease. While there are, of course, plenty of data relating to the first approach, there are no data at all on the second. We filled this gap in current knowledge and kept to the facts, irrespective of the pathophysiological mechanism concerned. That the lack of adrenal androgens in postmenopausal patients with Addison's disease essentially leads to the lack of substrate for peripheral conversion to oestrone and to osteoporosis, and that this is the salient point, seems obvious from our painstaking efforts to show whether this in fact resulted in lowered oestrone concentrations (two tables in our paper). This is so obvious to us that we concluded a recent abstract by stating that "the adrenal androgen play an essential role in the maintenance of bone mass after the menopause in providing the essentia precursors for oestrone."12 Our conviction has been strengthened by, among others, another study from Leeds, in which dehydroepiandrostenedione had no effect on bone, ${ }^{13}$ as well as by the numerous correlations between oestrone concentrations on the one hand and many densitometric variables on the other. That premenopausal patients with Addison's disease did not have osteoporosis showed that adrenal steroids play no part as long as oestrogens are present. Therefore little can be learnt by giving oestrogens to women with postmenopausal osteoporosis, as suggested by Dr Crilly.

With regard to replacement doses of glucocorticoids in postmenopausal patients with Addison's disease, we do not agree that they have a crucial role. We showed, as did Dr Crilly in his 1981 thesis, that premenopausal women were well protected against the administration of low dosage prednisolone, but this increased bone loss in men by a factor of $8 \cdot 3-10 \cdot 0$, whereas it did so in postmenopausal women by a factor of $1 \cdot 8-2 \cdot 6$. $^{14}$ Thus if replacement doses of glucocorticoids were important in this model the men ought to have had osteoporosis, which they did not.

\section{J P DEVOGELAER}

J CRABBE

C NAGANT DE DEUXChaISNES

Departments of Rheumatology and

Endocrinology,

St-Luc University Hospital,

Louvain University,

1200 Brussels,

\section{Belgium}

1 Urist MR, Vincent PJ. The excretion of various fractions of the 17-ketosteroids in the urine in women with postmenopausa or senile osteoporosis. Clin Orthop 1961;18:199-208.

2 Hollo I, Feher T. Studies on postmenopausal osteoporosis. I. Urinary excretion of 17-ketosteroid fractions in postmenopausal osteoporosis. Acta Med Hung 1964;20:233-6.

3 Hollo I, Feher T, Szücs J. Serum dehydroepiandrosterone, androsterone and cortisol level in primary postmenopausal androsterone and cortisol level in primary postmenopausal

4 Marshall DH, Crilly RG, Nordin BEC. Plasma androstenedione and oestrone levels in normal and osteoporotic postmenopausal women. BrMed f 1977;ii:1177-9.

5 Nordin BEC, Peacock M, Crilly RG, Francis RM, Speed R, Barkworth S. Summation of risk factors in osteoporosis. In DeLuca HF, Frost HM, Jee WSS, Johnston CC Jr, Parfit $\mathrm{AM}$, eds. Osteoporosis: recent advances in pathogenesis and treatment. Baltimore: University Park Press, 1981:359-67.

6 Johnston CC Jr, Norton JA Jr, Khairi RA, Longcope C. Age related bone loss. In: Barzel US, ed. Osteoporosis II. New York: Grune and Stratton, 1979:91-100.

7 Manolagas SC, Andersen DC; Lindsay R. Adrenal steroids and the development of osteoporosis in oophorectomised women. Lancet 1979; ii:597-600.

8 Davidson BJ, Ross RM; Paganini-Hill A, Hammond GD, Siiteri PK, Judd HL. Total and free estrogens and androgens in postmenopausal women with hip fractures. I Clin Endocrinol Metab 1982;54:115-20.

9 Davidson BJ, Riggs BL, Wahner HW, Judd HL. Endogenous cortisol and sex steroids in patients with osteoporotic spinal fractures. Obstet Gynecol 1983:61:275-8.

10 Riis BJ, Rodbro P, Christiansen C. The role of serum concentrations of sex steroids and bone turnover in the development and occurrence of postmenopausal osteoporosis. Calcif Tissue Int 1986;38:318-22.

11 Longcope C, Baker RS, Hui SL, Johnston CC Jr. Androgen and estrogen dynamics in women with vertebral crush fractures. Maturitas 1984;6:309-18.

2 Devogelaer JP, Crabbé J, Nagant de Deuxchaisnes C. Bone mineral density in Addison's disease. Evidence for an action of adrenal androgens on bone mass. Journal of Bone Mineral Research 1987;2(suppl 1): 94 .

13 Nordin BEC, Marshall DH, Francis RM, Crilly RG. The effects of sex steroids and corticosteroid hormones on bone. 7 Steroid Biochem 1981;15:171-4.

4 Nagant de Deuxchaisnes C, Devogelaer JP, Esselinckx W, et al. The effect of low dosage glucocorticoids on bone mass in rheumatoid arthritis: a cross sectional and longitudinal study using single photon absorptiometry. Adv Exp Med Bio 1984;171:209-39.

Problems of comprehensive shared diabetes care

SIR,-Dr J L Day and coworkers (20 June, $\mathrm{p} 1590$ ) describe the problems of caring for diabetic patients in general practice, not the problems of comprehensive shared diabetes care, as the title of their paper suggests, as the only support given to participating practices in their study was "at least one (practice) member at one meeting" to discuss their project. Thereafter general practitioners were expected to provide the same level of services that the clinic had provided to greatly increased numbers of patients. As other studies have shown, this results in the type of problems that Dr Day and colleagues describe, as (with the exception of antenatal care) general practitioners do not usually provide this type of service. Follow up of long term medical problems is usually "opportunistic" and, given the time constraints on general practitioners, not fully recorded. ${ }^{2}$ Indeed, recording of results is a problem for all doctors concerned with diabetes care. Dornan et al showed that $69 \%$ of patients attending hospital clinics had no record of foot examination in the past year compared with $90 \%$ of patients attending a diabetes miniclinic in their own practice. ${ }^{3}$ Where no framework existed these figures fell to $26 \%$ of patients attending their general practitioner irregularly and $17 \%$ for those attending only on a demand basis.

There are essentially three problems for general practitioners who want to provide long term follow up for their diabetic patients, and consultants who want to establish "comprehensive shared diabetes care" must address all three.

The first criterion, of organising follow up, is obviously possible, as has been shown by Hill ${ }^{4}$ and others. ${ }^{5}$ An investment in computers is probably necessary in both the coordinating hospitals and the participating practices. Though many practices have computers, the software for effective follow up is not always available.

The next problem is deciding on agreed examination criteria, which is more difficult to achieve, as previously discussed. Doctors are not good at performing regular testing. The suggestion by $\mathrm{Dr}$ Day and coworkers that nurses might participate is one solution. This may be done on a miniclinic basis or during regular surgery hours if a nurse performs most of the checks and the patient attends one of the partners in the practice for completion of the examination. This is the system used in my own practice, which achieves almost universal coverage of all our diabetic patients at least yearly.

The last problem is that of screening for retinopathy. This is the most difficult, as most general practitioners perceive their skills in funduscopy as being inadequate. Like many hospital doctors who are not ophthalmologists, general practitioners 